\title{
FUNDAMENTOS CONSTITUCIONAIS DA IGUALDADE DE GÉNERO
}

\author{
Sónia Fertuzinhos \\ Instituto Universitário de Lisboa (ISCTE-IUL), Lisboa, Portugal
}

Resumo: A Constituição da República de 1976 consagra pela primeira vez no ordenamento constitucional português a igualdade de direitos das mulheres. Este artigo analisa a evolução dos fundamentos constitucionais da igualdade de género ao longo dos 40 anos da Constituição e das suas sete revisões, a partir da literatura e dos debates parlamentares. A rutura com a experiência constitucional anterior, especialmente com a de 1933, e a dimensão transformadora da Constituição saída da revolução estão na base do papel fundamental que esta última teve e tem na promoção da igualdade de género e das políticas públicas desta área. A densificação da vertente da igualdade de género no princípio da igualdade, marcada pela cada vez maior exigência de uma igualdade fáctica e não apenas formal, ilustra e acompanha o percurso dos direitos das mulheres. O estudo deste percurso permite identificar vários pontos para debate e aprofundamento em futuros trabalhos de investigação. Desde logo a influência da participação de Portugal no projeto europeu e em diferentes organizações internacionais, bem como a relevância do papel de distintos atores no processo de construção do texto constitucional em matéria da igualdade de género, com particular destaque para as organizações de mulheres.

Palavras-chave: Constituição, princípio da igualdade, igualdade de género, políticas públicas.

Abstract The 1976 Constitution included equal rights for women in Portuguese constitutional law for the first time. This article uses the literature and the texts of parliamentary debates to analyse the evolution of the constitutional bases for gender equality over the 40-year life of the Constitution and its seven reviews to date. The break with the previous constitutional experience, especially that of 1933 , and the transformative dimension of the Constitution that arose from the 1974 revolution are at the roots of the key role the latter had and has in promoting gender equality and public policies in this area. The densification of the gender equality dimension of the principle of equality, marked by increasing demand for factual and not just formal equality, illustrates and accompanies the path taken by women's rights. The study of that path makes it possible to identify several points for discussion and deepening in future research, including the influence of Portugal's participation in the European project and in different international organisations, and the importance of the role of different actors in the process of constructing the constitutional text in the gender equality field, with particular attention to women's organisations.

Keywords: Constitution, principle of equality, gender equality, public policies.

Résumé La Constitution de 1976 consacre pour la première fois dans l'ordre constitutionnel portugais l'égalité des droits des femmes. Cet article analyse l'évolution des fondements constitutionnels de l'égalité de genre au long des 40 années de la Constitution et de ses sept révisions, à partir de la littérature et des débats

parlementaires. La rupture avec l'expérience constitutionnelle précédente, en particulier avec celle de 1933, et la dimension transformatrice de la Constitution issue de la révolution sous-tendent le rôle-clé que cette dernière a eu et a encore dans la promotion de l'égalité de genre et des politiques publiques dans ce domaine. La

densification de la dimension de l'égalité de genre dans le principe de l'égalité, marquée par l'exigence croissante d'une égalité de fait et pas seulement formelle, illustre et accompagne le parcours des droits des femmes. L'étude de ce cours permet d'identifier plusieurs points de discussion et d'approfondissement pour la recherche future, tels que l'influence de la participation du Portugal au projet européen et à différentes organisations internationales, ainsi que l'importance du rôle de différents acteurs dans le processus de construction du texte constitutionnel en matière d'égalité de genre, en mettant l'accent sur les organisations de femmes.

Mots-clés: Constitution, principe de l'égalité, égalité de genre, politiques publiques.

Resumen La Constitución de 1976, establece por primera vez en el orden constitucional portugués la igualdad de derechos de las mujeres. Este artículo analiza la evolución de los fundamentos constitucionales de la igualdad de género en los 40 años de la Constitución y sus siete revisiones, de la literatura y de los debates parlamentarios. La ruptura con la experiencia constitucional previa, especialmente con la de 1933, y la dimensión transformadora 
de la Constitución están en la base del papel clave que tuvo y tiene en la promoción de la igualdad de género y de políticas públicas en esta área. La densificación de la dimensión de la igualdad de género en el principio de igualdad, marcado por la creciente demanda de una igualdad de hecho y no sólo formal, ilustra y acompaña el curso de los derechos de las mujeres. El estudio de este curso permite identificar varios puntos de discusión y profundización para futura investigación. Inmediatamente, la influencia de la participación de Portugal en el proyecto europeo y en diversas organizaciones internacionales, así como la relevancia del papel de los diferentes actores en el proceso de construcción del texto constitucional en el ámbito de la igualdad de género, con especial atención a las organizaciones de mujeres.

Palabras-clave: Constitución, principio de igualdad, igualdad de género, políticas públicas.

\section{Breve introdução aos fundamentos constitucionais da igualdade}

Uma das matérias que ilustra e fundamenta, com especial clareza, a ideia de que a Constituição da República Portuguesa de 1976 "é certamente a mais original de todas as constituições portuguesas e aquela que mais marcadamente rompe com a Constituição precedente" (Canotilho e Moreira, 2014), é a que diz respeito à igualdade. No entanto, a definição do princípio geral da igualdade (artigo 13.ำ), a que se somaram, em 1976 e nas diferentes revisões constitucionais posteriores, várias "normas especiais" de igualdade, marca não apenas a rutura com a Constituição de 1933 do Estado Novo, como uma nova fase nos dois séculos de evolução histórica da exigência social, política, legal e constitucional relativamente ao conceito de igualdade (Amaral, 2004).

O princípio da igualdade é um princípio estruturante do constitucionalismo e do estado de direito, na sua relação com o princípio da liberdade e com a ideia de justiça, que é comum a todos os direitos e deveres fundamentais. É um princípio que marca o constitucionalismo moderno do final do século XVIII, como marca com igual relevância e constância o constitucionalismo português (Miranda e Medeiros, 2010). Desde as Bases da Constituição de 1821, que definem o princípio de que "a lei é igual para todos", que todas as Constituições e a Carta Constitucional que se lhe seguiram consagraram o princípio da igualdade: as Bases da Constituição de 1821, no artigo 11..; a Constituição de 1822, no artigo 9.. ; a Carta Constitucional de 1826, no artigo 145. ; a Constituição de 1838, no artigo 10..; a Constituição de 1911, no artigo 3.․, n.o 2; a Constituição de 1933, no artigo 5.‥

O reverso da medalha da "longevidade constitucional" deste princípio (Novais, 2011) é o da sua "construção gradual por camadas" (Amaral, 2004) até aos nossos dias. Construção que passou de um conceito de igualdade formal que convivia com a discriminação em função de certas categorias de pessoas - como as mulheres, os negros, os analfabetos ou com baixa instrução, os que professavam certas religiões - para um conceito de igualdade fática, que se obriga a ter em conta as diferenças entre as pessoas, tratando igual o que é igual, desigual o que é desigual, e que se preocupa com os resultados da lei.

A evolução do princípio da igualdade e do seu entendimento pela sociedade "conjuga dialeticamente" (Canotilho e Moreira, 2014) três dimensões. A primeira 
dimensão é a que resulta das Revoluções Liberais e da ambição e exigência de garantir a igualdade e a liberdade de todos perante a lei, contra os abusos e os privilégios do poder absoluto. As Declarações de Direitos e as Constituições escritas são a forma encontrada para garantir que estes dois princípios se irão concretizar materialmente (Garcia, 2005). Nesta primeira fase a igualdade é a igualdade de todos perante a lei, independentemente de quaisquer condições económicas, sociais ou outras. A igualdade é entendida como um valor absoluto e neutro. Esse entendimento deixava de fora os que não cabiam na "conceção particular" de cidadão da altura e discriminava em função de categorias de pessoas, como mulheres, negros, entre outros (Novais, 2011).

A segunda dimensão é a democrática e surge com a confrontação da "evidente hipocrisia" da igualdade universal do liberalismo, e com o reconhecimento de que a igualdade "seria, afinal, desigualdade" (Neto, 2009). Nesta fase é "redescoberto" o valor relativo da igualdade enquanto realidade construída, e a "máxima - todos são iguais perante a lei - pode decompor-se em duas afirmações distintas: o igual deve ser tratado igualmente e o desigual, desigualmente, na medida exata da diferença" (Garcia, 2005). Para resolver as questões que se colocam sobre o como definir "a medida exata da diferença" surge o conceito de discriminação (positiva e negativa) e o imperativo da proibição de discriminação como garantia da recusa do arbítrio legislativo (Amaral, 2004; Garcia, 2005; Canotilho e Moreira, 2014).

A terceira dimensão é a dimensão social que acompanha o desenvolvimento do alargamento das funções do estado em geral, e do estado social em particular. Trata-se da função social da igualdade (Canotilho e Moreira, 2014). A questão já não é, nesta fase, a da "igualdade perante a lei", mas a "igualdade da lei" e a sua capacidade para impor a igualdade material, no plano económico, social e cultural.

Nesta evolução, da proibição de discriminar na primeira dimensão do conceito de igualdade, à autorização de discriminar na segunda, impõe-se o objetivo de eliminar as desigualdades fáticas na terceira dimensão (Amaral, 2004; Canotilho e Moreira, 2014).

Sendo a igualdade um conceito valorativo, relativo e construído, a nossa perceção sobre o seu significado foi-se transformando ao longo do tempo (Amaral, 2004; Garcia,2005. A história da evolução do princípio da igualdade é assim a história de um princípio sempre "aberto, controverso e de compreensão não tão linear quanto uma evolução de 200 anos poderia fazer crer" (Novais, 2011).

De acordo com Novais (2011) a Constituição Portuguesa "acolhe expressa e eloquentemente todas as dimensões da igualdade e procura, tanto quanto possível, determinar normativamente a solução dos problemas de igualdade inevitavelmente suscitados por facto da complexidade que o princípio adquiriu no Estado Social".

São em número significativo os vários artigos da Constituição atual que incluem a palavra igualdade: o artigo 9. é e primeiro e determina como "tarefas fundamentais do Estado [...] d) Promover [...] a igualdade real entre os portugueses $[\ldots]$ h) Promover a igualdade entre mulheres e homens"; no artigo 10.. , "O povo exerce o poder político através do sufrágio universal, igual [...]"; no artigo 36.o , “1. 
Todos têm direito de constituir família e de contrair casamento em condições de plena igualdade $[\ldots] 3$. Os cônjuges têm iguais direitos e deveres quanto à capacidade civil e política e à manutenção e educação dos filhos"; no artigo $50 .$. , noำ, “Todos os cidadãos têm o direito de acesso, em condições de igualdade e liberdade, aos cargos públicos"; no artigo 58. . , "[...] 2. Para assegurar o direito ao trabalho, incumbe ao Estado promover: [...] b) A igualdade de oportunidades na escolha da profissão ou género de trabalho [...]; no artigo 74. ${ }^{\text {, " }}$ "1. Todos têm direito ao ensino com garantia do direito à igualdade de oportunidades de acesso e êxito escolar"; no artigo 109.o " “[...] devendo a lei promover a igualdade no exercício dos direitos cívicos e políticos e a não discriminação em função do sexo no acesso a cargos políticos".

Como são várias e exaustivas as "dimensões densificadoras" (Canotilho e Moreira, 2014) do princípio da igualdade, desde logo a igualdade entre mulheres e homens em geral e no acesso aos cargos políticos em particular (artigo 9. ․ㅡ, alínea $h$, e artigo 109.o, respetivamente), a proibição da discriminação em função da raça e da orientação sexual (artigo 13. , n... 2), a proteção da maternidade e da paternidade (artigo 68. ${ }^{\circ}$ ), a valorização da língua gestual portuguesa (artigo 74. ․ n. ․ㅡ 2, alínea $h$ ), o reconhecimento de direitos a cidadãos da União Europeia e da Comunidade de Países de Língua Portuguesa (artigos 15.ํ, n.. 3, e n.ํ5), a proteção dos direitos dos trabalhadores e das organizações sindicais (artigos 59.․ e 55., , respetivamente), o acesso ao ensino (artigo $74 .{ }^{\circ}$ ).

A Constituição de República em vigor é a "expressão de um contrato social" que resulta de um "vasto e complexo compromisso" entre as forças políticas desde 1976, compromisso que foi confirmado e atualizado em cada uma das sete revisões constitucionais (Canotilho e Moreira, 2014). O princípio geral e as normas especiais da igualdade são um bom exemplo disso mesmo.

\section{Os fundamentos constitucionais da igualdade de género}

A dimensão transformadora da Constituição de 1976, que adota um "extenso catálogo" de direitos fundamentais por oposição à sua supressão na Constituição de 1933 e na vigência da ditadura (Canotilho e Moreira, 2014), consagra pela primeira vez, no ordenamento constitucional português, a igualdade de direitos das mulheres em todos os domínios (Neto, 2009). A Constituição saída da Revolução marca a rotura com todas as constituições anteriores. Se as constituições liberais e da Primeira República não mencionavam as mulheres e a sua interpretação perpetuava a desigualdade entre mulheres e homens, desde logo na participação política, a Constituição de 1933 considerava expressamente a situação das mulheres, tendo por base "as diferenças resultantes da sua natureza e do bem da família" (Miranda, 2006), diferenças que justificavam a sua discriminação em todas as dimensões sociais, económicas e políticas.

Nos 40 anos da Constituição da República os direitos das mulheres ganham centralidade jurídico-constitucional no conjunto dos direitos fundamentais (Novais, 2011), referindo a literatura a existência de um regime especial de igualdade 
na Constituição, que é o da igualdade entre mulheres e homens (Amaral, 2004). À densificação da vertente da igualdade de género do princípio da igualdade corresponde uma transformação impressionante do papel das mulheres e dos homens na sociedade portuguesa nas últimas quatro décadas. Do estatuto de mulheres dos chefes de família e de mães educadoras, que as retirava do espaço público e da participação política, porque imprescindíveis, subsumidas e submissas no espaço privado, as mulheres passaram a ocupar progressivamente todas as dimensões da vida em sociedade, ao mesmo tempo que o papel e o espaço de participação dos homens na vida privada, desde logo na partilha de responsabilidades no cuidar dos filhos, também evoluíram positivamente.

Há ainda um caminho a percorrer, mas é inegável e deve ser valorizado o percurso vencido, reconhecendo na Constituição "as traves mestras da política de género" (Neto, 2009). Nesse percurso transformador mudou a vida das mulheres e dos homens porque se alterou "intensa e profundamente o sentido do direito que a rege" (Amaral, 2004).

Os fundamentos constitucionais da igualdade de género estão nos artigos 9.ㅇ, alínea $h$ ("Tarefas fundamentais do Estado"), 13.. ("Princípio da igualdade"), 36. , n.. 3 ("Família, casamento e filiação"), 47. ("Liberdade de escolha de profissão e acesso à função pública"), 48.. ("Participação na vida pública"), 49.. ("Direito de

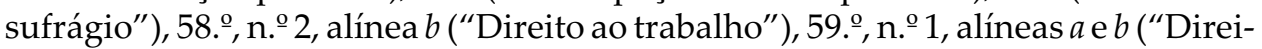
tos dos trabalhadores"), 67.․, n.. 2, alíneas $b, d$ e $h$ ("Família"), 68. ("Paternidade e maternidade") e 109.. ("Participação política dos cidadãos").

A promoção da igualdade entre homens e mulheres como tarefa fundamental do estado - artigo 9. $\stackrel{\circ}{n} n .^{.} 1$, alínea $h$

A introdução da promoção da igualdade entre homens e mulheres como tarefa fundamental do estado, no artigo 9.․ , n.. 1, alínea $h$, foi aprovada na VII revisão constitucional em 1997, na sequência da proposta do Partido Ecologista Os Verdes. A influência do Tratado de Amesterdão é assumida pelo partido proponente.

O sentido desta norma é o de "habilitar constitucionalmente" os poderes públicos para a adoção de medidas de discriminação positiva, com o objetivo da concretização da igualdade entre mulheres e homens (Pinheiro e Fernandes, 1999). O reconhecimento da igualdade em geral, e da igualdade entre mulheres e homens em particular, como uma realidade construída, impõe ao estado a promoção da igualdade fática, para além da igualdade formal. Se a eliminação das discriminações legais da ordem jurídica portuguesa foi concretizada logo nos primeiros anos a seguir à Revolução de 1974, antes e depois da Constituição de 1976, a construção de facto da igualdade entre mulheres e homens revela-se um objetivo mais difícil de dar por concluído (Garcia, 2005). Por reconhecer isto mesmo, o legislador aceita a necessidade de compensar materialmente as desigualdades fáticas entre mulheres e homens (Moreira, 1998).

Enquanto tarefa do estado esta norma tem, assim, duas dimensões (Canotilho e Moreira, 2014). Por um lado, e enquanto fim principal dos poderes públicos, impõe constitucionalmente a eliminação das desigualdades materiais e formais através da 
ação explícita do estado. Por outro lado, constitui um limite negativo à atuação dos poderes públicos, dependendo a validade dos seus atos da conformidade com o objetivo de promoção da igualdade entre mulheres e homens (artigo 3. ${ }^{\circ}$ ).

Até à revisão constitucional de 1997 a licitude das medidas de discriminação positiva era considerada "assaz problemática" (Moreira, 1998). O preceito constitucional da alínea $h$ do artigo 9.․ é a "credencial constitucional" (Moreira, 1998) que responde e resolve os problemas e dúvidas de fundamentação legal das medidas de discriminação positiva.

A análise do debate parlamentar deixa muito clara a intenção do legislador com a introdução desta norma. Na oposição e único voto contra está o CDS, que pela voz da deputada Maria José Nogueira Pinto considera que a igualdade entre homens e mulheres já está consagrada no artigo 13. da Constituição, que a sua inclusão no artigo 9. e é "colocar o problema na gaveta", falhar as prioridades, "reconhecer a derrota" na promoção dessa igualdade e "tratar as mulheres como minoria", quando as mulheres são "quantitativa [...] e qualitativamente" uma maioria que lutará cada vez mais "pela diferença do que pela igualdade". Na maioria o PEV e o PSD deixam muito claras as razões e os objetivos que justificam a necessidade desta norma na Constituição. A deputada Isabel Castro do PEV responde às críticas do CDS quanto à não justificação desta norma especial tendo em conta o artigo 13. ${ }^{\circ}$, dizendo: "Na verdade, não se trata [...] de um direito cuja incorporação no texto constitucional não faz sentido, pois este já consagra o direito de não discriminação em função do sexo. Trata-se de algo radicalmente diferente: a incumbência do Estado de promover a igualdade. A promoção da igualdade não é uma questão linear, não é uma fórmula, é no fundo a reformulação do próprio conceito de democracia política." A deputada Eduarda Azevedo do PSD afirma o principal objetivo desta norma: "Queremos crer que, de hoje em diante estará criado o enquadramento para acabar com o fosso existente e subsistente entre o direito proclamado e a prática existente. A simples igualdade decorrente do artigo 13. ${ }^{\circ}$ não tem chegado."

Este debate revela uma curiosidade que merece registo. A proposta inicial do PEV referia "a promoção da igualdade entre mulheres e homens" e a redação final e atual fixou a "promoção da igualdade entre homens e mulheres". Esta alteração deve-se ao acordo entre o PS e o PSD para que prevalecesse o critério da ordem alfabética na redação. Os argumentos das proponentes de que as mulheres constituem a maioria da população e de que o facto da desigualdade histórica ser a das mulheres em relação aos homens justificava que a ordem fosse mulheres e homens, foram vencidos.

$$
\text { O princípio da igualdade - artigo 13. }{ }^{\circ}
$$

Na vigência "intranquila" da Constituição de 1976, desde logo na sua formulação literal, o artigo 13. ${ }^{\circ}$ apresenta-se até hoje como tendo sido alterado apenas uma vez, em 2004, 28 anos depois da aprovação do texto original da Constituição democrática (Amaral, 2004). Essa única alteração acrescentou a orientação sexual ao conjunto de "categorias suspeitas" que motivam a discriminação entre as pessoas. Tendo em 
conta a importância do princípio da igualdade no constitucionalismo, que o transforma no "virtual guardião de todos os restantes valores constitucionais" a estabilidade deste artigo ao longo dos 40 anos da Constituição é especialmente relevante (Amaral, 2004).

A "tranquilidade" da redação do artigo 13. é mais percetível se o compararmos com o artigo 9..$^{\circ}$ referido no ponto anterior. Na redação atual, das oito tarefas do estado apenas a alínea $a$ corresponde à versão de 1976.

A análise da redação do artigo 13.ำ pode ser dividida em quatro partes: a dignidade social como base constitucional do princípio da igualdade e a igualdade dos cidadãos perante a lei, relativas ao n. ${ }^{-}$1, a igualdade de todos os cidadãos em matéria de direitos e deveres e a proibição de discriminações, relativas ao n. 2 .

A base constitucional do princípio da igualdade é a igual dignidade social de todos os cidadãos (Miranda e Medeiros, 2010; Canotilho e Moreira, 2014). É porque todos os cidadãos têm a mesma dignidade que devem ser tratados como iguais, independentemente da sua condição económica, social e política. O princípio da igualdade não garante assim o mesmo tratamento, mas um tratamento como igual (Novais, 2011).

A garantia do tratamento como igual associada à igualdade perante a lei, também enunciada no artigo 13. ${ }^{\circ}$, n.. 1 , muda completamente o sentido tradicional liberal desta expressão. Do princípio da igualdade que se subsumia no princípio da legalidade (Amaral, 2004), evolui-se para uma leitura do mesmo princípio que passa a significar a igualdade na lei e através da lei, só sendo legalmente possíveis as diferenciações fundamentadas em critérios que não colidam com "a igual consideração e respeito devidos a todas as pessoas" (Novais, 2011). Deixa assim de ser possível a convivência entre o princípio constitucional da igualdade e as discriminações pela generalidade da lei, como acontecia antes da Constituição de 1976.

O princípio da igualdade, no n.. 2 do artigo 13.. , enuncia um conjunto de fatores de discriminação ilegítimos, reconhecidos historicamente como justificados em razões que atentam contra a dignidade e o reconhecimento devidos a todas as pessoas, porque se baseiam unicamente em atributos sobre os quais as pessoas não têm controlo, ou em opções e orientações de vida individuais que as pessoas são livres de formar (Novais, 2011; Canotilho e Moreira, 2014). São os chamados grupos "suspeitos", já referidos anteriormente, e correspondem a alguns dos elementos fundadores de diferenças de tratamento jurídico que, não esgotando todos os fatores de discriminação, são socialmente reconhecidos como sendo, pela história e pela frequência, os mais significativos (Canotilho e Moreira, 2014).

Ainda no n. 2 do artigo 13.. , o princípio da igualdade traduz-se na regra da generalidade na atribuição de direitos e imposição de deveres, ou seja, os direitos e vantagens devem beneficiar todos, como os deveres e encargos devem obrigar todos (Canotilho e Moreira, 2014).

Na sua evolução, o sentido fundamental do princípio da igualdade assume uma dupla vertente (Miranda e Medeiros, 2010). A vertente negativa, que proíbe quaisquer privilégios e discriminações, e a vertente positiva, que abrange cinco dimensões: o tratamento igual de situações iguais, o tratamento desigual de situações substancial e objetivamente desiguais, o tratamento das situações relativamente iguais ou desiguais 
de acordo com o princípio da proporcionalidade, o tratamento das situações não apenas como existem mas como devem existir e, finalmente, a consideração do princípio da igualdade não como uma "ilha", mas na sua relação com os valores e padrões materiais da Constituição (Miranda e Medeiros, 2010).

Coloca-se ainda a questão de saber como avaliar e medir o igual e o desigual, como corrigir a desigualdade, como garantir a igualdade. A jurisprudência constitucional distingue três dimensões no controlo do respeito pelo princípio da igualdade (Amaral, 2004; Miranda e Medeiros, 2010; Garcia, 2005; Canotilho e Moreira, 2014). A primeira dimensão é a da proibição do arbítrio, que se traduz na imposição de tratar como igual o que é igual e tratar como diferente o que é diferente. A segunda dimensão é a da proibição da discriminação, tal como expressa no n. $\stackrel{2}{2}$ do artigo 13.. Finalmente, a terceira dimensão é a da obrigação de diferenciação, e concretiza-se pela introdução de discriminações ou medidas positivas, que têm como objetivo compensar as desigualdades de oportunidades.

O debate parlamentar traduz, de uma forma muito clara, a preocupação dos deputados e das deputadas com a igualdade de facto, para além da igualdade formal, e com a introdução de novos fatores reconhecida e comprovadamente discriminatórios, para além dos já consagrados na Constituição, como o estado civil e o estado de saúde. As sucessivas propostas de incluir o estado civil no n. $\underline{2}$ do artigo 13.. , foram justificadas pelos proponentes (PCP e deputada Helena Roseta do PPD) com base nas denúncias pelas associações de mulheres da discriminação real e persistente destas no mercado de trabalho. A sua rejeição teve na base o argumento de que os "grupos suspeitos" já adotados não esgotavam, nem poderiam esgotar, todas as situações, mas que respondiam à exigência de serem os mais abrangentes e consensualmente reconhecidos.

A especificação da não discriminação da igualdade entre mulheres e homens no texto do artigo 13.․ para além da não discriminação em função do sexo, é outra questão que motivou várias propostas do PCP. Propostas que tinham o apoio e que se somavam aos contributos das associações de mulheres, designadamente da Associação Portuguesa de Mulheres Juristas e da Intervenção Feminina. Estas iniciativas nunca conseguiram reunir a maioria necessária para a sua aprovação, sendo a justificação fundada na discussão sobre os limites e razoabilidade das especificações das normas constitucionais, em que a maioria do parlamento considerou a não discriminação em função do sexo abrangente e claramente orientada para a garantia da defesa da igualdade entre mulheres e homens.

Família, casamento e filiação - artigo $36 . \stackrel{\circ}{,} n . \stackrel{0}{ } 3$

O princípio da igualdade dos cônjuges, declarado no n. 3 do artigo $36 . .^{\circ}$, assume uma "expressão qualificada" do princípio da igualdade de direitos e deveres entre mulheres e homens, decorrente do n.. 2 do artigo 13.․ (Beleza, 1977; Canotilho e Moreira, 2014). Os cônjuges são iguais, sendo proibida qualquer discriminação jurídica na sua relação. O princípio da igualdade abrange assim, não apenas os direitos civis e políticos, mas também a família e as relações familiares. A família tem um valor constitucional próprio, mas não se sobrepõe ao direito à igualdade, 
liberdade, personalidade e dignidade de cada um dos seus membros (Miranda e Medeiros, 2010; Canotilho e Moreira, 2014).

A adoção do princípio da igualdade dos cônjuges, logo na Constituição de 1976, impõe o princípio da direção conjunta da família e rompe com a discriminação das mulheres na esfera familiar na Constituição de 1933 e numa extensa legislação do Estado Novo, que tinha como uma das suas missões "reeducar as mulheres" para a sua função imprescindível de educadoras e suporte da vida familiar (Pimentel, 1999), que condicionava o papel das mulheres ao "bem da família" (artigo 5. da Constituição de 1933). Este princípio implicou diretamente profundas alterações dos grandes códigos, como o Código Civil de 1966, de uma extensa legislação avulsa e a caducidade do maior número de normas do direito ordinário que consagravam, por exemplo, a figura do chefe de família, a impossibilidade de as mulheres casadas trabalharem ou saírem do país sem autorização do marido, o direito do marido de administrar não apenas os bens do casal, mas os da propriedade exclusiva das mulheres e até a possibilidade de perda da nacionalidade portuguesa, dependendo da nacionalidade do homem com quem as mulheres casassem (Beleza, 1977; Canotilho e Moreira, 2014; Miranda e Medeiros, 2010).

No debate parlamentar da Assembleia Constituinte, o n. 3 do artigo 36.. foi votado por unanimidade e sem discussão. Nas declarações de voto é realçado o sentido de correção de desigualdades históricas e da mais elementar justiça para as mulheres, na adoção do princípio da igualdade dos cônjuges. A deputada Hermenegilda Pereira do PCP traduz na sua declaração o objetivo e alcance da aprovação deste artigo, na concretização imediata da igualdade entre mulheres e homens na família: "Esta disposição vai ter profundas implicações no direito da família".

Esta norma constitucional e as alterações que impôs na restante legislação, como já referido, são tão mais importantes quanto a desigualdade das mulheres na família alimentava e "justificava" a desigualdade das mulheres no acesso à educação, ao trabalho e às profissões, no acesso e no exercício da participação política (Beleza, 1977; Amaral, 2004).

Liberdade de escolha da profissão e acesso à função pública - artigo 47.ํㅜ

A consagração do direito constitucional a "[...] escolher livremente a profissão ou o género de trabalho $[\ldots]$ ", reflete o princípio da igualdade, que neste artigo da Constituição se traduz na proibição de discriminações no acesso às diferentes profissões (Canotilho e Moreira, 2014). Não há nenhuma razão que fundamente a restrição no aceso às profissões e à função pública, desde logo em função do sexo.

Este direito assume duas dimensões e implica várias liberdades (Miranda e Medeiros, 2010; Canotilho e Moreira, 2014). Uma dimensão negativa que, enquanto direito de defesa, significa não ser forçado a escolher e exercer uma determinada profissão, nem ser impedido de escolher e exercer qualquer profissão para a qual se esteja habilitado. Uma dimensão positiva que implica, na relação deste direito com o direito ao trabalho e ao ensino, o direito à obtenção das condições legalmente exigidas para o exercício da profissão pretendida, e o direito de garantia de igualdade nas condições de acesso a cada profissão. 
A liberdade de escolha da profissão implica ainda diferentes liberdades (Canotilho e Moreira, 2014). A liberdade de aprender para obter as habilitações literárias necessárias ao exercício da profissão pretendida (artigo 43. ${ }^{\circ}$ ), liberdade de deslocação e residência no território nacional (artigo 44..$^{\circ}$, n.․ำ), a liberdade de emigração (artigo 44.. n. ${ }^{\circ}$ ), a liberdade de escolha do local de trabalho e a liberdade de exercício associado da profissão (artigo $46 . .^{\circ}$ ).

Se a proibição de qualquer discriminação em função do sexo, ou de qualquer outra, é claramente assumida, há concretizações desta mesma norma consideradas controversas (Canotilho e Moreira, 2014). É o caso do recurso às ações ou discriminações positivas para promover a igualdade de género no acesso às profissões, favorecendo o sexo menos representado, ou o caso de quotas mínimas que garantam o acesso de determinados grupos a certos cargos ou empregos, como as pessoas com deficiência na função pública. Em Portugal existem quotas na administração pública para a contratação das pessoas com deficiência, e discute-se hoje na concertação social as quotas para mulheres nos cargos de direção das empresas de maior dimensão.

Os debates parlamentares sobre este artigo foram bastantes consensuais, evidenciando três preocupações recorrentes. A preocupação com a diferença entre profissão e trabalho e a necessidade da inscrição dos dois termos, a dimensão de igualdade de oportunidades que deve ser garantida com a aprovação desta norma e a necessidade de garantir a transparência no acesso à função pública.

Na relação específica deste artigo com a igualdade de género, a sua importância em 1976 explica-se pelo facto de durante o Estado Novo várias profissões estarem vedadas às mulheres, como a magistratura, ou estarem condicionadas pela proibição de casarem, como a enfermagem e o ensino, não esquecendo que a lei do contrato individual de trabalho discriminava explicitamente o acesso das mulheres a qualquer emprego ou profissão em nome da "salvaguarda da sua saúde e moralidade ou para defesa da sua família (Decreto-Lei n.․ 49.408, de 24 de novembro, artigo 119.o) (Beleza, 1977; Viegas, 1977). Por outro lado, como as mulheres eram menos qualificadas e tinham ainda menos acesso ao ensino e à formação profissional, as implicações das dimensões e liberdades contidas nesta norma, já referidas, assumiram uma relevância especial na criação de condições para a liberdade de escolha de profissão das mulheres.

\section{Direito de sufrágio - artigo 49.ำ}

Em Portugal as primeiras eleições por sufrágio universal foram as eleições para a Assembleia Constituinte em 1975. O direito do sufrágio é, de acordo com o artigo 49.. da Constituição, universal para todos os cidadãos maiores de 18 anos, traduzindo a concretização dos princípios da generalidade e da igualdade (artigos $12 .{ }^{\circ} \mathrm{e}$ 13. ${ }^{\circ}$ ). O direito de sufrágio, sendo universal, é pessoal, presencial e definido como um dever cívico (Miranda e Medeiros, 2010).

O sufrágio restrito a certos cidadãos, de acordo com critérios com base no sexo, etnia, religião, habilitações, condição económica, entre outros, que marcou grande parte do estado liberal representativo até à Revolução de Abril, ficou 
definitivamente para trás com esta norma constitucional (Canotilho e Moreira, 2014). O direito das mulheres a elegerem e serem eleitas em absoluta igualdade relativamente aos homens, depois dos compromissos não assumidos na Primeira República e das restrições do Estado Novo relativamente às eleições locais, foi estabelecido na Constituição de 1976.

Direitos dos trabalhadores - artigo 59.,$n .^{.} 1$, alíneas a e b, e n..$^{\circ}$, alínea $c$

A Constituição reafirma de novo, nesta norma, o princípio fundamental da igualdade, rejeitando discriminações entre os trabalhadores em função da "idade, sexo, raça, cidadania, território de origem, religião, convicções políticas ou ideológicas".

O n.. 1 do artigo 59.․ fixa um conjunto de direitos dos trabalhadores que são muito importantes do ponto de vista da promoção da igualdade de género no mercado de trabalho. A definição do princípio de que para trabalho igual salário igual e o direito à organização do trabalho que permita a conciliação da vida profissional e familiar.

O n. 2 enumera um conjunto de incumbências do estado que permitam criar as condições para a concretização dos direitos dos trabalhadores definidos no n. ${ }^{\circ} 1$. As incumbências do estado com maior impacto na concretização da igualdade de género são a fixação do salário mínimo, mas também a definição da proteção especial, através da diferenciação positiva e de tratamento mais favorável, das mulheres grávidas.

Esta norma não se limita, assim, a proclamar uma simples igualdade formal, pelo contrário determina a criação de condições que garantam uma real igualdade de oportunidades para todos os trabalhadores em geral, e para as mulheres em particular (Beleza, 1977).

A importância desta disposição constitucional para a promoção da igualdade entre mulheres e homens no mercado de trabalho, em 1976, é óbvia, quando a participação das mulheres no mercado de trabalho era bem mais reduzida, as suas qualificações eram baixas e os setores de atividade maioritariamente femininos pagavam salários baixos, quando o casamento e a responsabilidade exclusiva das mulheres enquanto "fadas do lar" as afastava e excluía do acesso ao mercado de trabalho (Beleza, 1977). Hoje, como em 1976, apesar da evolução que deve sempre ser realçada, o princípio de salário igual para trabalho igual ainda não está garantido, sendo referido na literatura como um "princípio moribundo" (Miranda e Medeiros, 2010).

No debate parlamentar a introdução do princípio da conciliação da atividade profissional com a vida familiar, como um direito dos trabalhadores, teve origem na proposta da Associação Portuguesa de Mulheres Juristas no âmbito da revisão constitucional de 1997.

O princípio da conciliação da atividade profissional com a vida familiar surge pela constatação das várias discriminações das mulheres no mercado de trabalho, no acesso ao emprego, na remuneração, na estabilidade contratual, como consequência da "dupla jornada de trabalho" (Moreira, 2011). A elevada participação das mulheres no mercado de trabalho após o 25 de Abril implicou a acumulação 
das responsabilidades domésticas e do cuidar dos filhos com as responsabilidades profissionais, por ausência de respostas que substituíssem uma parte dessas tarefas. Este princípio desenvolvido nos anos 80 e 90 ao nível do direito comunitário, parte do princípio de que a igualdade entre mulheres e homens no mercado de trabalho não é possível sem uma maior partilha na família e na sociedade das responsabilidades familiares, desde logo no cuidar dos filhos (Moreira, 2011).

Na sua concretização o princípio da conciliação tem vários instrumentos de política, como a flexibilização dos horários, o recurso a tempo parcial, o investimento em estruturas de apoio às famílias, as licenças parentais que promovam a partilha do cuidar dos filhos entre as mães e os pais. A literatura chama, no entanto, a atenção para a possibilidade de estes e outros instrumentos poderem ter efeitos contraditórios com o objetivo da promoção da igualdade das mulheres e dos homens no mercado de trabalho e na partilha das responsabilidades domésticas, se não forem utilizados tantos pelos homens como pelas mulheres (Pinheiro e Fernandes, 1999). Medidas que obriguem à não transferibilidade de direitos são um dos meios para evitar potenciais efeitos contraproducentes. A licença de parentalidade em Portugal é um exemplo de política pública que traduz não apenas o objetivo de garantir tempos diferentes para os pais e para as mães no cuidar dos filhos, como diferencia positivamente (com mais tempo de licença) quem utiliza a totalidade dos tempos definidos para os dois progenitores.

$$
\text { Família - artigo } 67 . \stackrel{\circ}{,} n . . .92 \text {, alíneas } b, d \text { e } h
$$

O n..$^{\circ} 1$ do artigo 67. ㅁ da Constituição, cuja redação atual foi aprovada na revisão constitucional de 1982, reconhece ao mesmo nível a família enquanto instituição com direito à proteção do estado e da sociedade, e a família enquanto instituição que existe para a realização pessoal e individual dos seus membros (Miranda e Medeiros, 2010; Canotilho e Moreira, 2014). A rutura da Constituição de 1976 com a Constituição de 1933 é radical. A família deixa de se sobrepor aos seus membros, deixa de haver uma definição constitucional da família legítima e ilegítima, sendo reconhecidas todas as formas de organização familiar para além do casamento, as mulheres assumem um estatuto de igualdade, não estando os seus direitos e estatuto condicionados "em função da sua natureza e do seu papel na família", e cessa a distinção entre filhos legítimos e ilegítimos.

O n. .2 do artigo 67.. exemplifica algumas das responsabilidades e incumbências do estado na proteção da família, concretizando o que se define no n. ${ }^{\circ} 1$. Das oito alíneas desta norma, as alíneas $b, d$ e $h$ são bases importantes para as políticas públicas com o objetivo de promover a igualdade de género.

A alínea $b$ estabelece como responsabilidade do estado "promover a criação e garantir o acesso a uma rede nacional de creches e de outros equipamentos de apoio à família, bem como uma política para a terceira idade". Atribuindo o artigo 67.. a responsabilidade da proteção da família ao estado e à sociedade, esta norma não determina a criação de uma rede pública de creches, ao contrário do que é definido na Constituição relativamente ao ensino (artigo 75.ํ) (Moreira e Medeiros, 2010). 
A alínea $d$ resulta na sua redação atual da revisão constitucional de 1997, e refere a incumbência do estado de assegurar o direito ao planeamento familiar e à promoção do exercício da maternidade e paternidade responsáveis, no respeito pela liberdade individual.

A alínea $h$ foi introduzida na revisão constitucional de 2004 e assume duas dimensões. Por um lado, impõe a articulação de diferentes políticas setoriais com o objetivo de promover a conciliação da vida profissional e familiar. Por outro lado, legitima a possibilidade de discriminações positivas a favor da família.

O debate parlamentar desta norma, desde logo no n. ${ }^{\circ}$, é controverso e marcado pela recusa absoluta de qualquer referência à família que pudesse recuperar a noção e o papel da família da ideologia e da estratégia política do Estado Novo. Na Assembleia Constituinte a proposta do PSD e do CDS, de definir a família como elemento natural e fundamental da vida em sociedade foi rejeitada. O deputado Luís Nunes do PS refere na justificação do voto contra do PS, "o que aqui está [...] a nossa história torna-o mau. Porque o elemento natural da família é uma formulação que, historicamente, está situada na esteira do imperialismo lusitano e dos elementos naturais". É por esta ordem de razão que na versão da Constituição de 1976 o n.. 1 deste artigo referia apenas a proteção e o reconhecimento da constituição da família pelo estado. Nem mesmo invocando a Declaração Universal dos Direitos Humanos, que diz "A família é o elemento natural e fundamental da sociedade e tem direito à proteção desta e do Estado", os proponentes conseguiram ver aprovada a sua proposta.

Na revisão de 1982 a solução de consenso entre a direita e a esquerda neste debate parte da conciliação de uma proposta da AD - "A família é o elemento natural e fundamental da sociedade" - e de uma proposta do PCP - "As famílias têm direito à efetivação de todas as condições que permitam a realização pessoal de todos os membros do agregado familiar". Na discussão, a preocupação de deixar bem claro que não cabe na Constituição a definição de família, e que esta não se sobrepõe aos direitos de cada um dos seus membros é ainda fortemente marcada pela memória da Constituição de 1933 e do anterior regime.

Na revisão de 1989 , não sendo aprovada nenhuma das alterações ao n. ${ }^{\circ} 1$ propostas, a preocupação do legislador de clarificar o sentido da redação da norma, que reconhece a família, mas que esta é apenas uma das dimensões da vida dos indivíduos, ocupa de novo boa parte do debate parlamentar, afastando mais uma vez qualquer conceção de família que pudesse aproximar-se da ideia transpersonalista da mesma. A deputada Helena Roseta defendeu a necessidade de o debate constitucional ser um debate pedagógico e de o texto constitucional, para além da sua "pureza jurídica", ser também um "marco na evolução das mentalidades", porque facilmente se passa da defesa da "família como base da sociedade" para a "mulher como base da família". A revisão de 1989, não tendo aprovado nenhuma alteração ao n. 1 do artigo 67. , clarificou unânime e intencionalmente o espírito e a interpretação do legislador relativamente ao mesmo.

Os debates das alíneas $b$ e $d$ são sobretudo marcados pela questão do maior ou menor papel do estado na sociedade e na família.

O debate sobre a responsabilidade do estado de "promover a criação de uma rede nacional de creches e de outros equipamentos de apoio à família" é desde o 
início um debate entre os que defendem que ao estado cabe apenas "promover" essa rede porque é reconhecido o papel das instituições sociais (PSD, CDS e PS) e os que consideram ser essa uma responsabilidade direta do estado (PCP, UDP). Mas também entre os que consideram que as creches são uma opção de política inquestionável no apoio à família e na promoção da participação das mulheres no mercado de trabalho (PS, PCP), e os que defendem não saber, como o deputado Sousa Tavares do PSD, "até que ponto uma rede materno-infantil (redação da Constituição de 1976) não evoluirá no futuro para soluções que não são as de creches propriamente ditas. Porque inclusivamente, os países onde mais de desenvolvem os sistemas de creches - Suécia e Rússia - chegaram à conclusão de que não conseguiam cobrir mais de $30 \%$ da população infantil, por mais esforços que fizessem. E há bastantes dúvidas sociológicas sobre se se devia tentar outras fórmulas ou se se deve insistir no sistema de creches."

A discussão sobre o papel do estado em matéria de planeamento familiar é um debate que se traduz na evolução do tratamento desta questão pelos diferentes partidos, ao longo do tempo e em cada uma das revisões constitucionais. Se em 1976 os que defendiam o planeamento familiar como um direito se opunham a que o estado tivesse algum papel na efetivação desse direito, porque a intervenção do estado numa questão da estrita esfera individual não era desejável nem defensável (deputado Jorge Miranda do PSD), em 1982 foi possível consensualizar a redação atual, que mesmo assim não obteve a unanimidade dos partidos com assento parlamentar. Diferentes entendimentos sobre os limites do que deve ser inscrito na Constituição foram, em 1982, a dificuldade na obtenção da unanimidade, desde logo relativamente à ideia da promoção pelo estado da "paternidade consciente". O deputado Jorge Miranda questionava o sentido dessa afirmação e a impossibilidade de o estado garantir esse objetivo através da sua inscrição na Constituição.

\section{Paternidade e maternidade - artigo 68..}

A consagração da igualdade dos pais e das mães nesta norma constitucional é consequência do princípio da igualdade entre mulheres e homens (artigo 13.ำ n.․․ 2) (Miranda e Medeiros, 2010; Canotilho e Moreira, 2014). O texto em vigor deste artigo, que resulta da revisão constitucional de 1982 relativamente aos nos 1 e 2, e da revisão de 1997 quanto ao n. ${ }^{\circ}$ 3, traduz uma evolução significativa na igual valorização constitucional e social da paternidade e da maternidade, e não apenas da maternidade, como acontecia na redação da Constituição de 1976.

O estado e a sociedade têm a responsabilidade e obrigação constitucional de proteger de igual modo as mães e os pais na sua relação com os filhos, seja qual for a forma de organização e o vínculo familiar, sem que sejam prejudicados por essa razão na sua realização profissional e participação cívica (Beleza, 1977; Canotilho e Moreira, 2014).

No debate da revisão constitucional de 1982, a evolução na redação deste artigo relativamente ao texto da Constituição de 1976 é explicitamente referida e assumida. A deputada Teresa Ambrósio do PS justifica, na declaração de voto do seu grupo parlamentar, a aprovação desta norma "pelo que representa de evolução 
cultural, social e de mudança de imagens e papéis que os indivíduos desempenham na sociedade". A deputada Margarida Salema do PSD refere-se à nova redação deste artigo como resultado "de um passo importante na transformação de uma norma essencialmente discriminatória, embora no sentido positivo, numa norma basicamente igualitária que prevê que, quer os pais, quer as mães, tenham direito à proteção da sociedade e do Estado na realização da sua insubstituível ação em relação aos seus filhos". Em 1976 o consenso sobre o papel insubstituível da mãe na relação com os filhos foi justificado, entre outros argumentos, pela "posição de especialistas e, enfim, pessoas qualificadas sobre o assunto" (deputado Luís Nunes do PS).

O n. 9 do artigo 68. ${ }^{\circ}$ contém dois objetivos diferenciados (Canotilho e Moreira, 2014). O primeiro refere-se ao direito à proteção especial de todas as mulheres durante a gravidez e após o parto. O segundo dirige-se exclusivamente às mulheres trabalhadoras que acumulam o direito à dispensa de trabalho por período adequado, sem perda de remuneração e regalias.

\section{Participação política dos cidadãos - artigo 109.ำ}

Na revisão constitucional de 1997, a aprovação do artigo 109. , que substituiu o artigo 112. , mudou tudo na abordagem constitucional da participação política dos cidadãos. Do anterior artigo 112.ำ só se manteve mesmo a epígrafe, o que também tem um significado que será analisado posteriormente.

O artigo 112. assumia simplesmente uma declaração de princípios sobre a imprescindibilidade da participação dos cidadãos na vida política para a consolidação do sistema democrático. O novo artigo 109. ำ não apenas explicita a cidadania como sendo a das mulheres e dos homens, cidadãs e cidadãos, como coloca lado a lado o duplo dever de imposição da promoção da participação das mulheres e dos homens no exercício dos direitos políticos e cívicos, e da não discriminação em função do sexo no acesso a cargos políticos (Moreira, 1998).

Se todos os artigos constitucionais dos direitos, liberdades e garantias de participação política se referem a todos os cidadãos, como destinatários dos mesmos, com o artigo 109. " "a cidadania passou a ter sexo" (Moreira, 1998 Amaral, 2004).

Sobre a relevância e alcance desta alteração é possível encontrar na literatura posições diametralmente opostas. Alexandre Pinheiro e Mário Fernandes (1999) classificam esta alteração como uma mera "proclamação igualitária", que "não traz nada de útil", cuja redação é "juridicamente pueril", sendo a manutenção da epígrafe a prova da "incompatibilidade entre a participação política dos cidadãos e a promoção da igualdade e combate à discriminação em função do sexo". Pelo contrário Vital Moreira (1998) explicita a utilidade jurídica desta "decomposição" da cidadania em função do sexo, que resulta da relação entre a epígrafe da norma que se refere aos cidadãos e a redação do texto que divide os cidadãos entre mulheres e homens, a partir do caso da inconstitucionalidade das quotas declarada pelo Tribunal Constitucional francês. O Tribunal Constitucional francês declarou inconstitucionais as quotas, por considerar que colocavam em causa o fundamento da representação política que se baseia no conceito de cidadão, e não na distinção 
entre mulheres e homens. Com a adoção do artigo 109. esta argumentação não seria procedente no caso português. É a própria Constituição que divide os cidadãos em cidadãs e cidadãos, como já referido.

Como mencionado a propósito da alínea $h$ do artigo 9.o, até à revisão constitucional de 1997 a constitucionalidade de medidas de ação positiva era generalizadamente questionável e duvidosa. Se resulta claro do n. 2 do artigo 13. ${ }^{\circ}$ a proibição da discriminação em função do sexo e a garantia da igualdade jurídica entre mulheres e homens, o mesmo artigo "parece impedir do mesmo modo qualquer medida de favorecimento jurídico destinada a atenuar a desigualdade fática no acesso feminino aos cargos públicos, no exercício de direitos políticos" e em todas as dimensões da vida em sociedade (Beleza, 1977; Moreira, 1998).

No entanto, e comparando os artigos 9. (alínea $h$ ) e 109., o alcance deste último é considerado mais exigente (Moreira, 1998). Se as medidas positivas fundamentadas na alínea $h$ do artigo 9. ${ }^{\circ}$ podem ter como objetivo apenas a promoção da igualdade entre mulheres e homens, o artigo 109.․․ remete para a concretização da igualdade efetiva no exercício dos direitos cívicos e políticos (Moreira, 1998).

A inclusão do conceito inovador de direitos cívicos, a par dos direitos políticos, traduz-se no alargamento do âmbito do artigo 109.ํ e na possibilidade de fundamentação de medidas de discriminação positiva. Vital Moreira (1998) propõe um entendimento dos direitos cívicos como os que resultam da participação na vida cívica, como os direitos de expressão, de manifestação, de reunião, de associação, bem como os direitos coletivos laborais e a liberdade sindical.

Vital Moreira (1998) defende que a relação entre a imposição de medidas positivas para a igualdade fática entre mulheres e homens na participação política e cívica, por um lado, e a não discriminação em função do sexo no acesso a cargos políticos, que remete para o artigo 13., por outro, aponta para a necessidade de as medidas positivas a adotar deverem ser a favor dos dois sexos (medida de discriminação bilateral) e não apenas a favor de um dos sexos (medida de discriminação unilateral). Ou seja, de acordo com o autor, se a Constituição assume como objetivo corrigir a sobrerrepresentação dos homens na vida política, procura garantir que dessa correção não resulta a sobrerrepresentação das mulheres.

As discriminações ou medidas positivas espelham a evolução do princípio da igualdade que não aceita discriminações, para a discriminação ao serviço da igualdade (Garcia, 2005). Esta evolução é atravessada por uma "tensão necessária entre igualdade e diferença e entre direitos individuais e identidades de grupos" (Garcia,2005). Toda a discussão em torno do papel e da admissibilidade das medidas de discriminação positiva em geral, e das quotas para mulheres no acesso à participação política em particular, é o espelho disso mesmo. Alexandre Pinheiro e Mário Fernandes (1999) assumem que recusam "liminarmente a invocação de argumentos históricos [...] que, com base numa discriminação negativa passada legitimem uma discriminação positiva presente. [...] O direito não pode ser uma vingança da história."

De referir ainda que a Constituição fundamenta e legitima com o artigo 109. . a promoção da igualdade efetiva das mulheres e homens na participação cívica e política, mas não define em concreto as medidas positivas a adotar, sendo essa uma 
responsabilidade e opção do legislador (Miranda e Medeiros, 2010; Canotilho e Moreira, 2014). As opções em matéria de medidas positivas dividem-se em medidas que têm como objetivo promover condições de partida que permitam a concretização da igualdade entre mulheres e homens, e medidas que se centram nos resultados alcançáveis e a alcançar nessa mesma concretização, como é o caso das quotas (Beleza, 1977; Moreira, 1998).

O debate parlamentar do artigo 109.. reflete bem os argumentos, muitas vezes radicalmente opostos, que o debate das medidas positivas com o objetivo da igualdade na participação política das mulheres e dos homens suscita.

A deputada Eduarda Azevedo do PSD, numa intervenção em que refere e desenvolve a ideia da democracia como um "processo evolutivo e persistente", afirma que "começa a generalizar-se a ideia de que não é correto falar em democracia em termos neutros, uma vez que os seres humanos são homens e mulheres iguais em direitos e dignidade, que devem gozar das mesmas oportunidades de realização", e argumenta o apoio do seu partido ao artigo 109.․ porque "se impõe democratizar a democracia". Ilustra que "É ao nível da esfera pública que mais se faz sentir a exclusão das mulheres [...] independentemente da proclamação da igualdade formal. Existe um fosso efetivo entre a igualdade proclamada e a igualdade vivida." No mesmo sentido de apoio, a deputada Natalina Moura do PS defende que com a aprovação desta norma a Constituição passa a "consagrar a participação direta e ativa dos homens e das mulheres como condição e instrumento fundamental da consolidação do sistema democrático". Refere ainda que "nas relações entre homens e mulheres, o exercício da cidadania plena exige, para além de um tratamento de não discriminação jurídica, política e social, que se garanta a aplicação de medidas positivas destinadas a corrigir as limitações de base social e cultural de que as mulheres ainda são alvo no tempo presente". O PCP, pela voz do deputado Luís Sá justificava o voto a favor com "o sentido de garantir cada vez mais a democracia paritária, que é o nosso objetivo, o fim de qualquer discriminação, seja de que natureza for, em relação à mulher, sobretudo num campo que deveria ser aquele em que a discriminação devia ser menos possível, que é exatamente o campo da participação política".

Completamente contra o artigo 109.o, o deputado Nuno Abecassis do CDS disse "Lamentar o retrocesso da nossa Constituição [...] as minhas colegas deputadas são iguaizinhas a mim, não precisando de quotas para se afirmar, porque têm qualidade mais do que suficiente. [...] Gostam de ter uma Constituição que é um catálogo de supermercado! [...] Não somos um país do terceiro mundo! [...] Daqui a algum tempo e pela mesma razão, talvez queiram alterar a Constituição para defender os homens."

A Assembleia da República aprovou em 2006 a proposta do governo que propunha a Lei da Paridade, que prevê o limiar de 33\% de representação mínima de cada um dos sexos. Votaram a favor o PS e o BE, votaram contra o PSD, o CDS e o PCP. O artigo 109.. constituiu a base legal para a apresentação da proposta de lei do governo, que referia no preâmbulo que "mais do que uma simples repetição por via legislativa do princípio da igualdade e de acesso a cargos políticos, [o artigo 109.․] implica sobretudo a promoção de medidas tendentes a uma igualdade 
efetiva. Não se trata de uma mera faculdade, mas de um verdadeiro dever de legislar".

\section{Conclusões}

A análise dos fundamentos constitucionais da igualdade de género, enquadrada no princípio geral da igualdade, permite várias conclusões e levanta várias questões para debate.

A primeira conclusão é que a Constituição da República Portuguesa teve e tem um papel fundamental, que se desenvolveu em dois tempos, na promoção da igualdade de género e das políticas públicas desta área.

O primeiro tempo corresponde à aprovação da Constituição de 1976. As discriminações das mulheres que decorriam da Constituição de 1933 e da lei em geral, na família, no acesso ao emprego e às profissões, no acesso à educação, na participação cívica e política foram efetiva e permanentemente revogadas com a aprovação da Constituição de 1976. Os direitos das mulheres tiveram "modificações importantes por efeito do mero facto da entrada em vigor da Constituição" (Beleza, 1977).

Reconhecendo este facto, várias autoras (Beleza, 1977; Viegas, 1977) lamentam e chamam a atenção para o que a Constituição saída da Revolução de Abril deveria ter evitado e o que poderia ter feito melhor. Devia ter evitado, por exemplo, qualificar o papel insubstituível das mães na educação dos filhos (artigo 36. ${ }^{\circ}$, n.ํㅜ 3), quer pela controvérsia que sugeria, que ainda hoje sugere, quer porque reforçava "o peso dos estereótipos tradicionais" que alimentavam em efeito spillover, como ainda hoje, uma parte significativa de outras discriminações. Poderia ter feito melhor, pela aprovação de uma disposição de âmbito geral dos direitos das mulheres, que teria utilidade pedagógica, por um lado, e legitimaria, já nessa altura, as medidas positivas que fossem sendo consideradas necessárias na promoção da igualdade entre mulheres e homens (Beleza, 1977). Como poderia ter aprovado especificações da proibição da discriminação em função do sexo, referindo concretamente a proibição das discriminações entre mulheres e homens, por exemplo na consagração do princípio de salário igual para trabalho igual, ou mesmo no próprio princípio da igualdade, como propôs sucessivamente o PCP até à aprovação da promoção da igualdade entre mulheres e homens como uma incumbência do estado em 1997, na alínea $h$ do artigo 9.o (Beleza, 1977; Viegas, 1977).

O segundo tempo é o da evolução dos fundamentos constitucionais da igualdade de género ao longo das diferentes revisões constitucionais. Nesta evolução, quer a literatura científica, quer os debates parlamentares permitem identificar vários pontos e questões importantes. Neste trabalho propõem-se quatro.

Sem ter a intenção de elencar por qualquer tipo de ordem, o primeiro ponto é o da preocupação e exigência crescente com o efeito e o potencial das normas constitucionais na construção da igualdade material ou fática, na diminuição da distância entre a igualdade formal e a "igualdade real". Preocupação e exigência que acompanha a evolução e os paradoxos da igualdade entre mulheres e homens na sociedade (Ferreira, 1999). Da garantia da total liberdade no acesso ao emprego e à 
profissão, a constatação dos efeitos da "dupla jornada" das mulheres na persistência da desigualdade no mercado de trabalho "exigiu" a consagração constitucional do princípio da conciliação da vida profissional e familiar. Do direito das mulheres a votarem e a serem eleitas, a persistência da desigualdade da participação das mulheres na política "exigiu" a aprovação do artigo 109.., que abriu caminho às medidas positivas que acelerassem a democracia paritária. Partindo da norma geral do princípio da igualdade (artigo 13.․) e da garantia da não discriminação em função do sexo, a persistência das desigualdades económicas e sociais das mulheres "exigiu" a aprovação da promoção da igualdade entre mulheres e homens como uma "incumbência" do estado (artigo 9.. , alínea $h$ ).

O segundo ponto é o da importância decisiva dos preceitos constitucionais relativos à igualdade de género, na adoção e evolução das políticas públicas e na transformação da realidade económica, social e cultural na perspetiva da igualdade entre mulheres e homens. A obrigação constitucional de fixação do salário mínimo na Constituição de 1976 teve um impacto determinante no aumento dos rendimentos das mulheres e na redução das desigualdades salariais e melhoria das condições de trabalho pela alteração das contratações coletivas (Beleza, 1977; Viegas, 1977). A consagração do princípio da conciliação da vida profissional e familiar, combinada com as normas dos direitos dos trabalhadores (artigo 59..$^{\circ}$ ) e da paternidade e maternidade exigiu um novo impulso nas políticas de criação de estruturas de apoio às famílias, como as creches e o pré-escolar, nas políticas educativas, como a escola a tempo inteiro, nas políticas na área do emprego, como a definição das licenças para o pai para além das licenças da mãe, ou o reforço dos direitos laborais para o acompanhamento dos filhos. A lei da paridade resulta obviamente do artigo 109.․ ("Participação política dos cidadãos").

Na relação entre todas as normas constitucionais e o objetivo da promoção e da concretização da igualdade entre mulheres e homens há ainda todo um conjunto de políticas que são adotadas. A criação de organismos públicos com o objetivo de produzirem informação e conhecimento e monitorizarem as políticas públicas, como a Comissão para a Igualdade no Trabalho e no Emprego ou a Comissão para a Cidadania e a Igualdade de Género, e a já quase tradição da obrigatoriedade de a questão da igualdade assumir a forma de pasta governamental, seja numa secretaria de estado ou num ministério. A aprovação de Planos para a Igualdade e de combate à violência doméstica, que definem, de forma transversal a várias áreas, políticas e objetivos para a promoção e concretização da igualdade de género, ou a aprovação de planos de outras áreas governativas que incluem especificamente a questão da igualdade de género, como os Planos de Emprego ou os Planos de Inclusão.

O terceiro ponto é o da impossibilidade de compreender a evolução constitucional e do quadro legislativo em geral relativo à igualdade entre mulheres e homens sem a análise da influência da nossa integração no projeto europeu e a influência de várias organizações internacionais, como a Organização Internacional do Trabalho (OIT), o Conselho da Europa e as Nações Unidas. Nos debates parlamentares a justificação de várias normas constitucionais assume a influência direta ou indireta destas organizações e dos documentos internacionais que vinculam Portugal. A consagração da promoção da igualdade entre mulheres e homens 
no Tratado de Amesterdão (artigo 26. ${ }^{\circ}$, n.ำ 3) influenciou a adoção deste objetivo como incumbência do estado na Constituição Portuguesa (artigo 9.ํ. alínea $h$ ) (Canotilho e Moreira, 2014). Diferentes convenções da OIT determinaram as exceções ao princípio da não discriminação, para garantirem a proteção das mulheres durante a gravidez e o parto (artigo 59. ${ }^{\circ}$, n. $\stackrel{\circ}{2}$, alínea c). O Conselho da Europa e as Nações Unidas, a Conferência de Pequim, a Convenção para a Eliminação de todas as Formas de Discriminação contra as Mulheres ou a Convenção Europeia sobre os Direitos do Homem, para dar alguns exemplos, são recorrentemente citados pelos legisladores e legisladoras, quer na Constituinte, quer nas diferentes revisões constitucionais.

O quarto e último ponto refere-se aos atores que, para além das e dos legisladores constitucionais, influenciaram em cada momento ao longo dos 40 anos o texto da Constituição da República Portuguesa em matéria de igualdade entre mulheres e homens. A partir dos debates parlamentares é de destacar o papel das organizações de mulheres. As propostas destas associações em geral, e da Associação Portuguesa de Mulheres Juristas em particular, são constantes e partem da persistência das desigualdades entre mulheres e homens como fundamentação para a especificação da promoção da igualdade de género em várias normas, para além da proibição da discriminação em função do sexo, para a consagração de medidas positivas em várias áreas e para a atualização da promoção da igualdade pela introdução, por exemplo, do princípio da conciliação da vida profissional e da vida

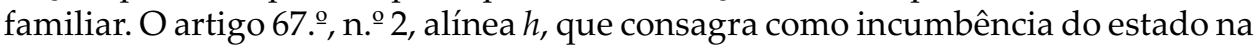
proteção da família a promoção da conciliação, resultou exatamente de uma proposta da Associação Portuguesa de Mulheres Juristas.

Para concluir, a evolução dos fundamentos constitucionais foi marcada pela vontade política, nem sempre unânime, mas claramente maioritária, para a sua aprovação, que exige dois terços dos deputados e deputadas, de aproximar cada vez mais a "igualdade real" da igualdade formal. A ideia de que temos uma das melhores legislações da Europa em matéria de igualdade entre mulheres e homens, mas que a diferença entre essa legislação e a realidade da vida das mulheres e dos homens é flagrante é recorrente e constante (Ferreira, 1999; Amaral, 2004; Garcia, 2005; Beleza, 2010). No entanto, é também consensual a certeza de que essa diferença é hoje clara e significativamente menor do que era há 40 anos, e que esse resultado se deve, desde logo, à Constituição. Basta pensar na presença das mulheres nos diferentes cargos políticos, seja no parlamento, nas câmaras e assembleias municipais, nos diferentes governos, ou na adesão dos homens à licença de paternidade.

Como referido no início, o princípio da igualdade é um princípio sempre aberto, cujos valores e ideias subjacentes são as das sociedades em cada momento (Garcia, 2005 Amaral, 2004; Novais, 2011). Se o caminho feito deve ser valorizado, o mesmo deve acontecer para o caminho que ainda falta fazer. O mote para os tempos que se seguem pode ser a persistência interpelante da desigualdade salarial, agravada pelo aumento da precariedade e pela queda dos salários nos anos após a crise de 2008, e dois dados do Inquérito à Fecundidade de 2013, que mostram a "perpetuação" do forte desequilíbrio de papéis familiares entre mulheres e homens e o facto de a maioria das 
mulheres (74\%) e dos homens (64\%) considerarem que a opção ideal para o pai é trabalhar a tempo inteiro, sendo o tempo parcial a opção ideal para a mãe.

\section{Referências bibliográficas}

Amaral, Lúcia (2004), "O princípio da igualdade na Constituição portuguesa", em Estudos em Homenagem ao Prof. Doutor Armando M. Marques Guedes, Coimbra, Coimbra Editora, pp. 35-57

Beleza, Maria Leonor (1977), "O estatuto da mulher na Constituição", em Jorge Miranda (coord.), Estudos sobre a Constituição, 1.․v vol., Lisboa, Livraria Petrony, pp. 63 ss.

Beleza, Teresa (2010), Direito das Mulheres e da Igualdade Social. A Reconstrução Jurídica das Relações de Género, Coimbra, Edições Almedina.

Campinho, Bernardo (2011), “Direitos políticos e igualdade de gênero: participação política feminina como construção democrática".

Canas, Vitalino, e outros (1998), Democracia com mais Cidadania. A Questão da Igualdade de Participação Politica, Lisboa, Presidência do Conselho de Ministros.

Canotilho, J. J. Gomes, e Vital Moreira (2014), Constituição da República Portuguesa Anotada, 2 vols., Coimbra, Coimbra Editora.

Carone, Iray, "Igualdade versus diferença: um tema do século".

Dray, Guilherme Machado (1999), O Princípio da Igualdade no Direito do Trabalho. Sua Aplicabilidade no Domínio Específico da Formação de Contratos Individuais de Trabalho, Coimbra, Edições Almedina.

Fermino, Crystiane Castellucci (2012), "A situação jurídica das mulheres em Portugal no pré e pós 25 de Abril, em especial no âmbito das relações familiares", trabalho de investigação no âmbito do 14..${ }^{\circ}$ Curso de Pós-Graduação em Direitos Humanos, Faculdade de Direito da Universidade de Coimbra.

Ferreira, Virgínia (1999), "Os paradoxos da situação das mulheres em Portugal”, Revista Crítica de Ciências Sociais, 52-53, pp. 199-227.

Garcia, Maria Glória F. P. D. (2005), Estudos sobre o Princípio da Igualdade, Coimbra, Edições Almedina.

INE, e Fundação Francisco Manuel dos Santos (2013), Inquérito à Fecundidade, Lisboa, INE e FFMS.

Magalhães, José, 1999, Dicionário da Revisão Constitucional, Editorial Notícias.

Miranda, Jorge (2006), Escritos Vários sobre Direitos Fundamentais, Cascais, Editora Principia.

Miranda, Jorge (2009), Manual de Direito Constitucional, 7 vols., Coimbra, Coimbra Editora.

Miranda, Jorge, e Rui Medeiros (2010), Constituição Portuguesa Anotada, 3 vols., Coimbra, Coimbra Editora (2. ․ㅡ edição).

Moreira, Vital (1998), “A IV revisão constitucional e igualdade de homens e mulheres no exercício de direitos cívicos e políticos (Notas sobre o artigo 109. da CRP)", Boletim da Faculdade de Direito, LXXIV, Universidade de Coimbra, pp. 407-431.

Moreira, Maria Margarida Góis (2011), O Princípio da Conciliação da Vida Profissional com a Vida Familiar. Algumas Considerações, Lisboa, Universidade Católica Portuguesa, dissertação de mestrado em Direito. 
Neto, Luísa (2009), “O direito e a igualdade de género”, Julgar, 8, pp. 161-177.

Novais, Jorge Reis (2011), Os Princípios Constitucionais Estruturantes da República Portuguesa, Coimbra, Coimbra Editora.

Pimentel, Irene (1999), "A assistência social e familiar do Estado Novo nos anos 30 e 40 ", Análise Social, XXXIV (151-152), pp. 477-508.

Pinheiro, Alexandre Sousa, e Mário João de Brito Fernandes (1999), Comentário à IV Revisão Constitucional, Lisboa, Associação Académica da Faculdade de Direito de Lisboa.

Ramalho, Maria do Rosário Palma (2007), “The importance of a balanced reconciliation of family and professional life between men and women for the practical implementation of gender equality principle in employment area", em Homenagem da Faculdadde de Direito de Lisboa ao Professor Doutor Inocêncio Galvão Telles, 90 Anos, Coimbra, Edições Almedina, pp. 909-919.

Rodrigues, Julieta de Almeida (1983), “Continuidade e mudança nos papéis das mulheres urbanas portuguesas: emergência de novas estruturas familiares", Análise Social, XIX (77-78-79), pp. 909-938.

Viegas, Lia (1977), A Constituição e a Condição da Mulher. Temas da Constituição / 6, Lisboa, Diabril.

Viegas, José Manuel Leite, e Sérgio Faria (1999), As Mulheres na Política, Lisboa, Presidência do Conselho de Ministros.

Outras fontes

Diários da Assembleia Constituinte relativos aos artigos referidos.

Diários da Revisão Constitucional de 1982, 1989, 1992, 1994, 1997, 2001, 2004 e 2005 relativos aos artigos referidos.

Sónia Fertuzinhos. Doutoranda em Politicas Públicas, ISCTE-IUL, Avenida das Forças Armadas, 1649-026 Lisboa. E-mail: semsf@iscte.pt 